\title{
Family Relationship of Children with Behavior
}

\section{Disorders}

\author{
Lama Majed Al-Qaisy \\ Department of Educational Psychology, Faculty of Educational Sciences, \\ Tafila Technical University (TTU), Tafila, Jordan. \\ E.mail: lamaqaisy@yahoo.com
}

\begin{abstract}
Jihad Turki
Department of Educational Psychology, Faculty of Educational Sciences, Tafila Technical

University (TTU), Tafila, Jordan.

E.mail: dr.alturk@hotmail.com
\end{abstract}

doi:10.5296/ijld.v1i1.1048

URL: http://dx.doi.org/10.5296/ijld.v1i1.1048

\begin{abstract}
The present study aims to determine the relationship of the families of children with childhood behavior disorders. In a sample of 263 students in the age group of 10-12 years studying in $4^{\text {th }}, 5^{\text {th }}$ and $6^{\text {th }}$ standards in the elementary schools of Tafila city. The researcher analyzed the family relationship of the three groups of families based on two factors such as cohesion and conflict. Investigator also compared these factors in the families of children with no behavior disorders, with that of families of children with mild and severe behavior disorders. The results of the study reveals that, a high cohesion and less conflict is found among the families of children with no behavior problems and low cohesion and conflict in the families of children with severe behavior problems.
\end{abstract}

Keywords: family, relationship, children, behavior disorders

\section{Introduction}

The growth and development of the child, is a continuous process that beings long before the child makes its entrance into this world. A child's development is mainly dependent on two factors, the heredity and the environment (Feinstein \& Bynner, 2004). The hereditary factors are determined at the time of conception and determined once and for ever. The environmental factors which influence the development of the child are two types. First, the prenatal environment and the second, the environment in which the child is born (Wilson, 1989). The prenatal environment is the one influence during the prenatal period where the physical and mental health of the mother, contributes to the growth and development of the 
foetus. Factors such as poor nutrition, infectious diseases, drugs, $\mathrm{Rh}$. Blood factor, age and emotional factors of the mother may contribute to abnormalities in the physical and mental health of the child (Rindfuss, \& Brewster, 1996, Elder \& Shanahan, 2007).

The second- the social environment- play a major role in determining the behavior of the child. This environment includes his family, neighbourhood, friends and the socio-cultural factors. Each society has its own set of rules and regulations or norms which people follow knowingly or unknowingly (Fussell \& Furstenberg, 2005). A particular behavior considered normal in one society may be stamped as a problem behavior in another society. Society also moulds him to develop certain moral, social and religious values (Feinstein \& Bynner, 2004). When a child conforms to the expectations of his parents and society, he is accepted and rewarded. But if he goes against any of the norms, he is punished and labeled as a problem child. Thus the socialization and the socio-emotional development of the child develop his behavior pattern. The socialization and socio-emotional development of the child is largely affected by the parental influences and the family experiences (Raley, Harris, \& Rindfuss, 2000).

The family as the unit of child rearing is universal. Rearing includes physical care, education, discipline and socialization. The child learns his first lessons of socialization within his family and his social behavior and attitudes reflect the treatment he receives from his parents in his home (Brown \& Herbert, 1997). The adult interaction with their child depends on their ethical and religious codes, their own emotional make up, desires, needs and frustrations in life. It is also influenced by family traditions, standards and surrounding community patterns (McCubbin, \& Barbara, 1985). The adjustments, family relations and natural attitudes of parents give the child an assurance of stability, security, emotional maturity and ability to adjust to new or unforeseen circumstances (Miller, Yorgason, Sandberg, \& White, 2003). Psychologically, it is significant that, the child is loved, wanted and accepted by his parents, as they are his main source of security. While dealing with a child, one should not lose sight of the importance of the family on the child's life. Parental attitudes and emotional climate of the family as a whole has profound influence on the growing child. In other words the dynamics of human interaction in the home provide the children with experience which lay the foundation for later adjustments (Marrjorie, Janice, Eija, Paivi \& Marita, 2003).

A behavior problem is a deviant behavior of a child which does not conform to the expectations of society and is considered detrimental to the welfare of self, family and the society (Manly, Cicchetti \& Barnett, 1994). Some of the major behavior problems seen commonly in growing children are lying, stealing, thumb sucking, bed wetting, temper-tantrums, shyness and submissiveness, truanting, scholastic backwardness, eating disorders, (anorexia or obesity) psychogenic vomiting, aches or pains, hyperactivity, stubbornness, fits, inferiority complex, jealousy, certain speech disorders, mental retardation, day dreaming, phobia, nail biting, nightmares and so on. Problems of children are receiving far more attention at the present time (Bolger \& Patterson, 2001). Among them, psychological problems are one entity. Nearly every child has psychological problem at some point in his life and this could be called a "behavior problem" of the child during that period (Clogg, 1995). Behavior problems are child's way of reacting to different environment, and 
are indeed a cry for help, perhaps a danger signal arising from adverse surrounding. Each child reacts to his/her environment in his/her own way when there is a clash between the two-the child and the environment-a behavior problem results (Bolger\& Patterson, 2001). Even if it is the same environment, reactions of different children are different. One child may develop a particular deviant behavior; another might develop another deviant behavior, while a third may not have any unusual behavior. Hence to understand the behavior of a child, every aspect of his life has to be thoroughly studied (Sandra, Grahan \& Susan, 1995). According to Manly, Kim, Rogosch \& Cicchetti (2001) there are three major ideas implicit in explaining human behavior. The first is the idea of "causality", the idea that, human behavior is caused. Causality is implied, in the belief that, environment and heredity affect behavior. Second is the idea of "directedness", the idea that, human behavior is not only caused, but is also pointed towards something-a goal. The third is the idea of "motivation". That underlying behavior there is a 'motive' or a 'need'.

\subsection{Reasons of Behavior Disorders}

The child is socialized through the interaction of the above environmental factors. This socialization process depends on the:

\subsubsection{Organic and physical statues of the child}

A child who enjoys good health is more confident and emotionally stable than a child who is physically weak or is suffering from certain abnormalities. Children suffering from physical illness and physical handicaps may feel inferior to healthy and normal children (Sher, 1991). This also may lead to behavior problems and scholastic backwardness and their partial or complete withdrawal from other members in the society. Boucher (1999) found that, children with behavior disorders are frequently found to have been more difficult babies' than their normal peers.

\subsubsection{Socio-cultural factors}

These factors include peer group, neighbourhood, the school environment and the cultural values of the society. Family is the primary agency for socializing the child. Then comes peer group, neighbourhood and school environment. Once the child begins to go to school, the behavior and the attitude of the teachers and school environment contribute to the development of child's personality. If he is in the company of antisocial behavior, there are more chances of his getting involved in these behaviors (Macmillan, 2005).

\subsubsection{Family}

Although a number of factors may be associated with the development and maintenance of behavior disorders in children, of primary importance is the family environment. That is, the moment-to-moment interactions, that, the child has with his or her primary care givers. Supporting this, a number of studies had been conducted on the family interaction patterns, family relationship especially between parents (Macmillan \& Eliason, 2003). Wolfe \& Mosk (1989) found that, children with behavior problems came from home with lack of parental union and lack of parental cohesion. Researchers focused on the multifactorial dimensions of psycho-social interactions of family, like relationship pattern, communication style, material dimensions, authority structure and role functioning on the development of behavior problems among children (Brennan, Hammen, Brocque \& Mcclure, 2001). The research into 
the treatment of behavior disorders strongly supports the view that, certain changes in the family environment conditions such as parenting styles, family stress arrest the problem behavior in children (Coyne \& Downey, 1991). Kerig (1998) found that, the children who feel free to confide with their parents showed better adjustment than their counterparts who could not freely confide with their parents. There is often the danger of parents denying each other. Pointing out each other's mistakes, pitfalls and inadequacies, and taking sides with children are situations dangerous for the healthy emotional development of the child. Rejection by the parents fosters a distorted and devaluated self concept and self image for the child. He may feel helpless, inferior and insecure according to Macmillan \& Copher (2005) parentally rejected children feel neglected, isolated and alone. They frequently attempt to gain acceptance and positive social relationships through a variety of attention seeking behaviors like temper tantrums, disobedience, lying, stealing etc, as reported by (Kerr, Lopez, Olson \& Sameroff, 2004). Marrjorie, et al (2003), Depaul, Joaguin, Arruabarrena \& Ignacia (1995) studied the school adjustment of children in relation to their family climate and found that, the parents of the maladjusted students had given them insecurity, rejection and monotony. Parents are assumed to function as role model for the child's adjustments to life if the parents are not well adjusted, this gives the child a poor model to imitate and is likely to load to problem behavior similar to that of his parents Herschell \& Mcneil (2005). It is reported by Meyer (1994), Michelle, Jims \& David (1999) that, parent child relationship in general, and mother child relationship in particular and her own personality is responsible for behavior disorders in children. Frye \& Garber (2005) reported that, if a mother herself suffered serious emotional deprivation in her childhood, essential mother love component is lacking and the baby in turn is subjected to the same pathogenic experiences as herself. De Bruyn, et al (2005) reported that, faulty attitudes, which stem from personality structure of the parents, are responsible for psychological problems among children. McCubbin \& Barbara (1985) found that, mothers of children with behavior disorders emit higher frequencies of commands to their children than mothers of children without any problem. Family structure is considered as the functioning and relationship among the family members. These two variables, family functions and family relationship constitute the family structure and it is assumed that, these variables are related to behavior disorders in children. According to Cicchetti \& Toth (1991) the configuration of the family determines the forms of behavior that are required in the roles of husband and wife, mother and child. The functions of a family have been found to vary over time, with the stage of development and with the life cycle of the family. The universal functions of the families are to provide sexual activity to raise children, to provide care, love and nurturing and discipline and to provide a supportive environment to the family. Function is the usage that has evolved from the contribution that an activity or an item makes the whole, the consequence of the activity or item for the system being considered (Macmillan \& Copher, 2005). Family functioning includes production activities, such as income generating activities, home making activities, learning activities, regarding social and cultural norms and expectations, education, health and nutrition, social activities, and cultural activities. As well as other activities by which family seeks to meet its own needs. If we consider the above activities of the families and their distribution among the family members, we find that, women may bear the responsibilities of household and child 
related functions and men may bear responsibilities for economic and remunerative activities (Miller, 1995). McCubbin and Barbara (1985) states the family functions as (1) to reproduce individuals (2) to protect its boundaries (3) motivate persons to take positions of leadership, and (4) to solve the economic problem of physical survival. Among these functions, some of them appear to be performed by the family in every society. These are called "universal family functions". Roditti (2005) speaks of reproduction, maintenance, placement and socialization (or raising the young) as universal family functions. Lasswell and Lasswell (1982) say the universal functions are reproduction, socialization, economic co- operation, and sexual relation. The term relatedness relating and relational system are referred to the qualities and patterns of the processes that take place between persons (Marrjorie, et al 2003). The family relationship is the relationship between father-mother, father-children, mother-children and children-children. These set of relationship exists in the family, but the quality of relating among these relationships vary as the process in the family changes. These processes occur in the families as a result of the relationship dimensions of interactions. Hence the researcher here assumes that, the relationship dimensions of group behavior which influence satisfaction of group members in their task performance exists in families also. Thus, the relationship dimensions are taken as the aspect of family, which influence the functioning of the families (Herschell and Mcneil, 2005).

The structure of families in the development of behavior problems among children are of paramount importance. The findings of the study may help the professionals in helping such families in solving the problems of their children by improving the functioning and relationship aspects of the family. Also the findings of the study may widen the scope of social work professionals in their work with children and their families. The present study aims to determine the relationship of the families of children with childhood behavior disorders.

\section{Hypotheses:}

1-There is a significant variation in the family relationship among the families of children with severe behavior disorders with that of families of children with mild and no behavior disorders.

This hypothesis is tested in terms of two factors of family relationship such as cohesion and conflict. Thus, the following sub- hypotheses were formulated:

a- There is a significant variation in the degree of cohesion in the families of children with severe behavior disorders with that of families of children with mild and no behavior disorders.

b- There is a significant variation in the degree of conflict in the families of children with severe behavior disorders with that of families of children with mild and no behavior disorders. 
3. Method

\subsection{Participants}

A total of 263 students in the age group of 10-12 years studying in $4^{\text {th }}, 5^{\text {th }}$ and $6^{\text {th }}$ standards in the elementary schools of Tafila city. A list of the schools that were willing to participate were then prepared. Marks obtained for all the papers for all the students of class 4, 5 and 6 . These marks were subjected for scrutiny and it is made sure that the student fits into the criteria set for high or low achiever. Then give the children Behavior checklist-B, to answer it and to their father or mother who is available at home using the tool to measure the Family structure and back it next day. The total sample comprised of 263 respondents (100) respondents in group 1 , families of children with no behavior disorders, group 2,(104), families of children with mild behavior disorders, group 3,(59), families of children with severe behavior disorders.

\subsection{Instruments}

\subsubsection{Behavior checklist:}

Behavior checklist of Achenbach (1997) is used. It is used to identify and classify children with behavior disorders and with no behavior disorders. The scale contains 26 statements to answer Always ( ) Sometime ( ) and Never ( ).

\subsubsection{Family relationship scale}

Family relationship scale of Bradley (1994) is used. It is contains factors of family relationship such as cohesion, conflict and neglect. The scale contains 30 statements to answer Always ( ) Sometime ( ) and Never ( ).

\subsection{Validation of the scales}

All the scales were supplied to 10 experts in the disciplines of psychology and sociology for face validity. They requested to read each item carefully and to state whether each item measured the factors specified. After that, the ambiguity and vagueness were corrected.

Reliability was established through test- retest method. For this, a group of 30 respondents were given this questionnaire. The same respondents were administered the questionnaire after two weeks. The original response and the second response were tested for Pearson correlation co-efficient. Result obtained .81, indicated a high and significant reliability of the tool.

\section{Result}

In order to find the variation relationship in the three groups of families, the following subhypothesis is formulated.

Hypothesis: there is significant variation in the degree of cohesion experienced in the families of children with severe behavior disorders with that of families of children with mild and no behavior disorders.

Table (1) Mean, and standard deviation in the degree of cohesion experienced in the families of children with no and mild behavior disorders scores 


\begin{tabular}{lcccc}
\hline \multicolumn{1}{c}{ Groups } & N & M & SD & SE \\
\hline Group1 no behavior disorders & 100 & 8.64 & 1.77 & .177 \\
Group2 mild behavior disorders & 104 & 8.43 & 1.78 & .175 \\
\hline
\end{tabular}

Table (2) T-test of cohesion experienced of the families of children with no and mild behavior disorders scores

\begin{tabular}{lccccc}
\hline \multicolumn{1}{c}{ Groups } & $\mathrm{N}$ & 2 Tail & $\mathrm{T}$ & $\mathrm{DF}$ & $\mathrm{F}$ \\
\hline Group1 no behavior disorders & 100 & .383 & .87 & 202 & 1.01 \\
Group2 mild behavior disorders & 104 & .383 & .87 & 201.78 & \\
\hline
\end{tabular}

Table (3) Mean, and standard deviation in the degree of cohesion experienced in the families of children with no and severe behavior disorders scores

\begin{tabular}{lcccl}
\hline \multicolumn{1}{c}{ Groups } & $\mathrm{N}$ & $\mathrm{M}$ & $\mathrm{SD}$ & $\mathrm{SE}$ \\
\hline Group1 no behavior disorders & 100 & 8.64 & 1.77 & .177 \\
Group3severe behavior disorders & 59 & 6.85 & 2.78 & .359 \\
\hline
\end{tabular}

Table (4) T-test of cohesion experienced of the families of children with no and severe behavior disorders scores

\begin{tabular}{lccccc}
\hline \multicolumn{1}{c}{ Groups } & $\mathrm{N}$ & 2 Tail & $\mathrm{T}$ & $\mathrm{DF}$ & $\mathrm{F}$ \\
\hline Group1 no behavior disorders & 100 & .000 & 5.08 & 157 & 2.31 \\
Group3severe behavior disorders & 59 & .000 & 4.58 & 88.18 & \\
\hline
\end{tabular}

Table (5) Mean, and standard deviation in the degree of cohesion experienced in the families of children with mild and severe behavior disorders scores

\begin{tabular}{lcccc}
\hline \multicolumn{1}{c}{ Groups } & $\mathrm{N}$ & $\mathrm{M}$ & $\mathrm{SD}$ & $\mathrm{SE}$ \\
\hline Group2 mild behavior disorders & 104 & 8.43 & 1.78 & .175 \\
Group3 severe behavior disorders & 59 & 6.85 & 2.78 & .359 \\
\hline
\end{tabular}

The results show that, the mean scores on cohesion between group 1 and group 2 are 8.64 and 8.43. Group 1 and group 3 are 8.64 and 6.85. The difference in the mean scores on cohesion between group1 and group 3, group2 and group 3 are suggestive of testing the significance of difference between them.

Table (6) T-test of cohesion experienced of the families of children with no and severe behavior disorders scores

\begin{tabular}{lccccc}
\hline \multicolumn{1}{c}{ Groups } & $\mathrm{N}$ & 2 Tail & $\mathrm{T}$ & DF & $\mathrm{F}$ \\
\hline Group2 mild behavior disorders & 104 & .000 & 4.50 & 161 & 2.28 \\
Group3severe behavior disorders & 59 & .000 & 4.04 & 87.4 & \\
\hline
\end{tabular}

The results of the t-test show that, the significance of variation between group 1 and group 3 are $\mathrm{t}$-value $=5.08, \mathrm{p}=0.000$ at 0.05 level, group 2 and group 3 are $\mathrm{t}$-value $=4.50, \mathrm{p}=0.000$ at 0.05 level. That means there is significant variation in the cohesion in the families of group 1 and group 3, group 2 and group 1.

To ascertain the results of t-test with regard to compare the variation in the cohesion in the 
three groups ANOVA test has been conducted.

Table (7) Mean, and standard deviation between the cohesion among the three groups of families.

\begin{tabular}{lcccc}
\hline \multicolumn{1}{c}{ Groups } & $\mathrm{N}$ & $\mathrm{M}$ & $\mathrm{SD}$ & $\mathrm{SE}$ \\
\hline Group1 no behavior disorders & 100 & 8.64 & 1.77 & .177 \\
Group2 mild behavior disorders & 104 & 8.43 & 1.78 & .175 \\
Group3 severe behavior disorders & 59 & 6.85 & 2.78 & .359 \\
Total & 263 & 8.15 & 2.13 & .131 \\
\hline
\end{tabular}

The results of table 4 show that the mean scores on cohesion seem to exhibit considerable variation, among the groups, more prominently between group 1 and group 3 with their average score at 8.43 and 6.85 . This variation in scores suggests a testing of the significance of difference between the degree of cohesion that characterize three groups.

Table (8) ANOVA to compare degree of cohesion among the three groups of families

\begin{tabular}{lccccc}
\hline \multicolumn{1}{c}{ Groups } & DF & $\begin{array}{c}\text { Sum of } \\
\text { squares }\end{array}$ & Mean squares & F- ratio & F \\
\hline Between Groups & 2 & 132.765 & 65.93 & 16.384 & .0000 \\
Within Groups & 260 & 1052.152 & 4.055 & & \\
Total & 262 & 1183.925 & & & \\
\hline
\end{tabular}

The results of one way ANOVA test reveal that the three groups of families of children with no behavior problems, mild behavior problems and severe behavior problems, do significantly differ on their respective scores on cohesion, as an indicator of their family relationship F- ratio $=16.384 \mathrm{P}=0.000$ at 0.05 level.

Hypothesis: there is significant variation in the degree of conflict in the families of children with severe behavior disorders with that of families of children with mild and no behavior disorders.

The result of mean scores between group 1 and group 2 on conflict are 4.46 and 4.55, between group 1 and group 3 are 4.46 and 6.41 and between group 2 and group 3 are 4.55 and 6.41. The results of the t-test show that, there is significant variation on the scores of the conflict between group 2 and group 3, t-value $=-5.35$ and between group 2 and group 3 , $\mathrm{t}$-value $=-4.77$

Table (9) Mean, and standard deviation in the degree of conflict experienced in the families of children with no and mild behavior disorders scores

\begin{tabular}{lcccl}
\hline \multicolumn{1}{c}{ Groups } & $\mathrm{N}$ & $\mathrm{M}$ & $\mathrm{SD}$ & $\mathrm{SE}$ \\
\hline Group1 no behavior disorders & 100 & 4.46 & 2.29 & .229 \\
Group2 mild behavior disorders & 104 & 4.55 & 2.68 & .254 \\
\hline
\end{tabular}

Table (10) T-test of conflict experienced of the families of children with no and mild behavior disorders scores 


\begin{tabular}{lccccc}
\hline \multicolumn{1}{c}{ Groups } & $\mathrm{N}$ & 2 Tail & $\mathrm{T}$ & $\mathrm{DF}$ & $\mathrm{F}$ \\
\hline Group1 no behavior disorders & 100 & .811 & -.24 & 202 & 1.28 \\
Group2 mild behavior disorders & 104 & .811 & -.24 & 201.59 & \\
\hline
\end{tabular}

Table (11) Mean, and standard deviation in the degree of conflict experienced in the families of children with no and severe behavior disorders scores

\begin{tabular}{lcccc}
\hline \multicolumn{1}{c}{ Groups } & $\mathrm{N}$ & $\mathrm{M}$ & $\mathrm{SD}$ & $\mathrm{SE}$ \\
\hline Group1 no behavior disorders & 100 & 4.46 & 2.29 & .229 \\
Group3severe behavior disorders & 59 & 6.41 & 2.37 & .309 \\
\hline
\end{tabular}

Table (12) T-test of conflict experienced of the families of children with no and mild behavior disorders scores

\begin{tabular}{lccccc}
\hline \multicolumn{1}{c}{ Groups } & $\mathrm{N}$ & 2 Tail & $\mathrm{T}$ & $\mathrm{DF}$ & $\mathrm{F}$ \\
\hline Group1 no behavior disorders & 100 & .000 & -5.35 & 157 & 1.07 \\
Group3severe behavior disorders & 59 & .000 & -5.30 & 118.39 &
\end{tabular}

Table (13) Mean, and standard deviation in the degree of conflict experienced in the families of children with mild and severe behavior disorders scores

\begin{tabular}{lcccc}
\hline \multicolumn{1}{c}{ Groups } & $\mathrm{N}$ & $\mathrm{M}$ & $\mathrm{SD}$ & $\mathrm{SE}$ \\
\hline Group2mild behavior disorders & 104 & 4.55 & 2.68 & .254 \\
Group3severe behavior disorders & 59 & 6.41 & 2.37 & .309 \\
\hline
\end{tabular}

Table (14) T-test of conflict experienced of the families of children with no and mild behavior disorders scores

\begin{tabular}{lccccc}
\hline \multicolumn{1}{c}{ Groups } & $\mathrm{N}$ & 2 Tail & $\mathrm{T}$ & $\mathrm{DF}$ & $\mathrm{F}$ \\
\hline Group2mild behavior disorders & 104 & .000 & -4.77 & 161 & 1.19 \\
Group3severe behavior disorders & 59 & .000 & -4.89 & 129.68 & \\
\hline
\end{tabular}

To ascertain the results of t-test with regard to conflict among the three groups of families, ANOVA test has been conducted.

Table (15) Mean, and standard deviation between the conflict among the three groups of families.

\begin{tabular}{lcccc}
\hline \multicolumn{1}{c}{ Groups } & $\mathrm{N}$ & $\mathrm{M}$ & $\mathrm{SD}$ & $\mathrm{SE}$ \\
\hline Group1 no behavior disorders & 100 & 4.46 & 2.29 & .229 \\
Group2 mild behavior disorders & 104 & 4.55 & 2.68 & .254 \\
Group3 severe behavior disorders & 59 & 6.41 & 2.37 & .309 \\
Total & 263 & 4.89 & 2.66 & .158 \\
\hline
\end{tabular}

The results of table 4 show that the mean scores on conflict seem to exhibit considerable variation, among the groups, more prominently between group 1 and group 3, with their average score at 4.46 and 6.41. This variation in scores suggests a testing of the significance of difference between the degree of cohesion that characterize three groups.

Table (16) ANOVA to compare degree of conflict among the three groups of families 


\begin{tabular}{lccccc}
\hline \multicolumn{1}{c}{ Groups } & DF & $\begin{array}{c}\text { Sum of } \\
\text { squares }\end{array}$ & Mean squares & F- ratio & F \\
\hline Between Groups & 2 & 182.567 & 91.244 & 15.432 & .0000 \\
Within Groups & 260 & 1537.31 & 5.913 & & \\
Total & 262 & 1719.795 & & & \\
\hline
\end{tabular}

The results of One Way ANOVA test reveal that, the three groups do significantly differ on their respective scores on conflict, as an indicator of their family relationship F- ratio $=15.432$ $\mathrm{P}=0.000$ at 0.05 level. This result accepted that the children in the three groups of families experience varying degrees of conflict in their family environment.

\section{Discussion}

The present study aims to determine the relationship in the families of children with childhood behavior disorders. The results of the study reveals that, a high cohesion and less conflict is found among the families of children with no behavior problems and low cohesion and conflict in the families of children with severe behavior problems. Depaul, Joaguin, Arruabarrena, and Ignacia (1995) reported that persistent conflict in intact families is also associated with behavior problems. Brown \& Herbert (1997) found in their study on children mental health, it is related to marital disruption and level of conflict in the family. Clinicians tend to assume that, relation $\mathrm{s}$ between the parents of behaviorally disturbed children are more conflictual and less egalitarian than those between the parents of better adjusted children. (Miller, 1995) found that inter parental conflict has been associated with behavior problems in children whether that conflict occurred in intact marriage, before divorce and after divorce.

\section{Conclusion}

The major findings emerged from the study is that, the families of children with severe behavior disorders and the families of children with mild and no behavior disorders differ significantly in their family functioning and family relationship. Hence the factors influencing the family functioning and family relationship should be changed in a progressive direction to gain good communication clarity, leadership and social support. There should be increased cohesion and decreased in conflict. The qualitative study of the families of children with no behavior disorders may yield results which help the therapists and psychiatric social workers to develop appropriate intervention strategies for the families of children with severe behavior disorders. 


\section{References}

Achenbach, T. M. (1997). Manual for the Young Adult Self-Report and Young Adult Behavior Checklist. Department of Psychiatry, University of Vermont.

Bolger, K., E and Patterson, C, J. (2001). Pathways from Child Maltreatment to Internalizing Problems: Perceptions of Control as Mediators and Moderators. Development and Psychopathology, Vol 13. P913-940.

Boucher, C. R. (1999). Students in Discord Adolescents with Emotional and Behavioral Disorders, Greenwood Press, Westport, CT.

Bradley, R. H. (1994). The Home Inventory: Review and reflections. Advances in Child Development, 25, 241-288.

Brennan, A., Hammen, C., Brocque, M. R., Mcclure, B. (2001). Parental Anexiety Disorders, Child Anexiety Disorders and the Perceived Parent- Child Relationship in an Austrelian High- Risk Sample. Journal of Abnormal Child Psychology, Vol 29. Issue 1. P1-18.

Brown, K., and Herbert, M. (1997). Preventing Family Violence. John Wiley and Sons. New York.

Cicchetti, D and Toth, L. (1991). Internalizing and Externalizing Expressions of Dysfunction, two edition, Publisher: Lawrence Erlbaum Associates, Hillsdale, $\mathrm{Nj}$.

Clogg, C. (1995). Latent class models. In G. Arminger, C. Clogg, \& M. Sobel (Eds.), Handbook of statistical modeling for the social and behavioral sciences (P 311 - 359). New York: Plenum Press.

Coyne, J., and Downey, L. (1991). Social Factor and Psychopathology Stress, Social Support, and Coping Processes. Annual Review of Psychology, Vol 42. P 401-420.

De Bruyn, J., Veerman, W., and Kroes, G. (2005). The Impact of the Big Five Personality Traits on Reports of Child Behavior Problems by Different Informants. Journal of Abnormal Child Psychology, Vol 33. Issue 2. P231-250.

Depaul, Joaguin., Arruabarrena, M., and Ignacia. (1995). Behavior Problems in School Aged Physically. Abused and Neglect Children in Spain. Child Abuse and Neglect, Vol 19. Issue 4. P409-422.

Elder, G. H., \& Shanahan, M. J. (2007). The life course and human development. In W. Damon \& R. M. Lerner (Eds.), the handbook of child psychology (6th Ed.). New York: Wiley.

Feinstein, L., \& Bynner, J., (2004). The importance of developmental trajectories in mid-childhood: Effects on adult outcomes in the UK 1970 Birth Cohort. Child Development, 75, 1329 - 1339.

Frye, A.A., and Garber, J. (2005). The Relations among Maternal Depression, Maternal Criticism and Adolescents Externalizing and Internalizing Symptoms. Journal of Abnormal Child Psychology, Vol 33. Issue 1. P1-12.

Fussell, E., \& Furstenberg, F. F. (2005). The transition to adulthood during the twentieth Century: Race, nativity, and gender. In R. A. Settersten, Jr., F. F. Furstenberg, \& R. G. Rumbaut (Eds.), On the frontier of adulthood. Theory, research and public policy (pp. 29 75). Chicago: University of Chicago Press.

Herschell, D., and Mcneil, B. (2005). Theoretical and Empirical Under Pinnings of ParentChild Interaction Therapy with Child Physical Abuse opulations. Education \& Treatment of 
Children, Vol 28. Issue 1. P142-155.

Kerig, K. P. (1998). Moderators and Mediators of the Effects of Interparental Conflict on Children's Adjustment. Journal of Abnormal Child Psychology, Vol 26. Issue 3. P235-250.

Kerr, R. D., Lopez, L. N., Olson, L. SH., and Sameroff, J. A. (2004). Parental Discipline and Externalizing Behaviors Problems in Early Childhood: the Roles of Moral Regulation and Child Gender. Journal of Abnormal Child Psychology, Vol 32. Issue 4. P349-369.

Lasswell,M.E., and Lasswell, T. E. (1982). Marriage and the Family, Washington, DC Press. Macmillan, R. (2005). the structure of the life course: Standardized? Individualized? Differentiated? Amsterdam: Elsevier.

Macmillan, R., \& Copher, R. (2005). Families in the life course: Interdependency of roles, role configurations, and pathways. Journal of Marriage and Family, 67, 858 - 879.

Macmillan, R., \& Eliason, S. (2003). Characterizing the life course as role configurations and pathways: A latent structure approach. In J. T. Mortimer \& M. J. Shanahan (Eds.), Handbook of the life course (pp. 529 - 554). New York: Plenum.

Manly, J.T., Cicchetti, D., and Barnett, D.(1994). The Impact of Subtype, Frequency, Chronicity, and Severity of Child Maltreatment on Social Competence and Behavior Problems. Development and Psychopathology, Vol 6. P121-143.

Manly, J.T., Kim, J., Rogosch, F, A., and Cicchetti, D.(2001). Dimensions of Child Maltreatment and Children's Adjustment: Contributions of Developmental Timing and Subtype. Development and Psychopathology, Vol 13. P759-782.

Marrjorie, W., Janice, G., Eija, P., Paivi, A., and Marita, P. (2003).Family Dynamics and Child Abuse and Neglect in Three Finish Communities. Mental Health Nursing, Vol 22. Issue 617. P707-716.

McCubbin, H., and Barbara, D (1985). Marriage and Family. U.S.A: John Wiley \& Sons, Inc.

Meyer, M.(1994). Personality Disorders, Inv. Ramachndram. (Ed.) Encyclopedia of Human Behavior, Three edition, New York: Academic Press.

Michelle, N., Jims, S., and David, S. (1999). Characteristics of Mothers of Boys Who Sexuality Abuse. Child Maltreatment, Vol 4. Issue 1. P11-21.

Miller, B. R., Yorgason, B.J., Sandberg, G.J., and White, B.M.(2003). Problems That Couples Bring to Therapy: A view A cross the Family Life Cycle. The American Journal of Family Therapy, Vol 31. P395-407.

Miller, B.S. (1995). When Parents Have Problems. A book for Teens and Older Children with an Abusive, Alcoholic, or Mentally Ill Parent, MDB. Ill- Milo Dept.

Raley, R., Harris, K., and Rindfuss, R. (2000). "The Quality and Comparability of Child Care Data in U.S. Surveys.” Social Science Research, 29:356-81.

Randolph, M. S. (1995). African American Children in Single-Mother Families. In B. J. Dickerson (Ed.), African American Single Mothers: Understanding Their Lives and Families (pp. 117-145). Thousand Oaks, CA: Sage Publications.

Rindfuss, R. R., and Brewster K. L. (1996). "Childrearing and Fertility.” Population and Development Review 22(Supplement):258-89.

Roditti, M. (2005). Under Standing Communities of Neglectful Parents: Child Care giving Networks and Child Neglect. Child Welfare League of American, Vol 2. P277-298. 


\section{Macrothink Institute ${ }^{\mathrm{TM}}$}

Sandra, G., Grahan, S., and Susan, H. (1995). Children's Understanding of Aggression and with Drawl as Social Stigmas: An Attributional Analysis. Child Development, Vol 25. Issue 1. P1250-1260.

Sher, K.J. (1991). Genetic and Environmental Influences. In: SHER, K.J.(Ed) Children of Alcoholics: A critical Appraisal of Theory and Research, Chicago, IL: University of Chicago Press.

Wilson, M. N. (1989). Child development in the context of the black extended family. American Psychologist, 44(2), 380-385. 